\title{
Distribution and development of embryos in the pig
}

\author{
L. L. Anderson and R. O. Parker \\ Department of Animal Science, Iowa State University, Ames, Iowa 50011, U.S.A.
}

\begin{abstract}
Summary. The distribution and development of pig embryos were determined in relation to the number of embryos and their positions within the uterine horn between Days 14 and 34 after mating. The observed distribution of 1-11 embryos within a uterine horn was highly correlated $(r=0.96)$ with the theoretical expected distribution. Embryo spacing was uniform regardless of the number of embryos within the horn. Nitrogen content of the embryo in relation to its position within the uterine horn indicated that development was similar for embryos located at the utero-tubal end or cervical end and comparable to those located in the middle portion of the horn. Placental development, as indicated by nitrogen content, was similar regardless of location within the horn.
\end{abstract}

\section{Introduction}

Fetal development in the pig depends upon the position and the number of fetuses within the uterine horn. Fetuses located near the utero-tubal junction and near the cervix are larger than those in the middle of the horn (Waldorf, Foote, Self, Chapman \& Casida, 1957; Perry \& Rowell, 1969). Differential growth of fetuses in relation to position within the uterine horn of the pig was evident particularly during late gestation (e.g. after Day 70) and when the number of fetuses exceeded 5 per horn. Legault \& Leuillet (1973) found similar relationships in placental weight, but not embryonic weight, by Day 30 of pregnancy; conceptuses were larger in the terminal positions when they exceeded 5/horn.

In the present investigation, the distribution and development of embryos were determined in relation to the number of embryos and their positions within the uterine horn during early pregnancy in the pig. Development of the conceptuses was evaluated by the amount of nitrogen in living embryos and placentae.

\section{Materials and Methods}

\section{Experimental animals}

Yorkshire and Yorkshire $\times$ Hampshire pigs, 5-7 months old and about $100 \mathrm{~kg}$ bodyweight, were checked daily for oestrous behaviour with boars. The first day of oestrus was designated Day 0 . All animals completed at least one normal oestrous cycle $(20 \pm 2$ days) before being mated at the third oestrus.

\section{Surgical procedures and analysis of embryonic development}

Ovariectomies and hysterectomies were performed through a midventral incision with aseptic surgical techniques as previously described (Anderson, 1975). Embryos were classified as living at Day 14 by embryological development, at Day 18 by embryological development and heart beat, and at Days 22-34 by heart beat. After separation of the embryo from the placenta each was freeze dried. Nitrogen was determined, in duplicate in each embryo and placenta, by a microKjeldahl method or by dividing the amount of protein (determination by the method of Lowry, Rosebrough, Farr \& Randall, 1951) by 6.25 (Anderson, 1975). 


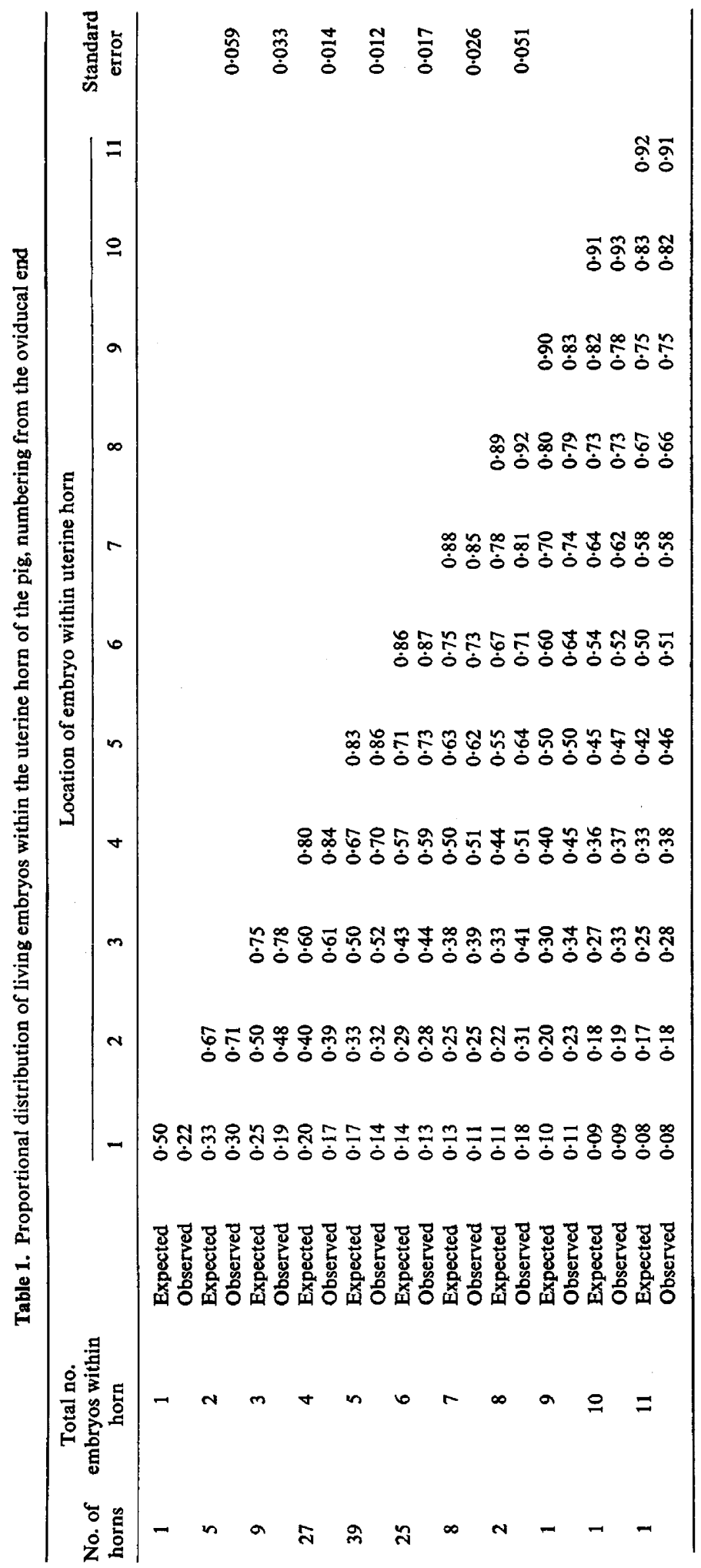


The length of each uterine horn was measured, and the distance from the utero-tubal junction to the first embryo (Embryo 1) was determined, as well as distances between embryos (Embryos 2 to $n$ ) and that distance from the last embryo (Embryo $n$ ) to cervix. The length of uterine horn was standardized to equal 1.0 , and the relative position of each embryo indicated as a proportional distance from the utero-tubal junction. The same numbering sequence was used to identify placentae; the first placenta (Placenta 1) was nearest the utero-tubal junction, and the last placenta (Placenta $n$ ) nearest the cervix.

The total nitrogen content of all living embryos within a uterine horn was expressed as $1 \cdot 0$, and the amount of nitrogen within one embryo in that horn as a proportion of the whole. Likewise, the total nitrogen in the placentae of all the living embryos in a horn was expressed as 1.0 , and that in one placenta as a proportion of the whole.

The data were analysed by the method of least squares for equal or unequal subclass size, where appropriate.

\section{Results}

The proportional distribution of the 1-11 embryos within one uterine horn after Day 14 is shown in Table 1. The observed distribution of embryos within a uterine horn was highly correlated $(r=0.96)$ with the theoretical expected distribution. Embryo spacing during implantation was uniform, regardless of the number of embryos within the horn. As the number of embryos increased, the proportional distance between them decreased. The living embryos were distributed nearer either end of the uterine horn in those horns containing 1-7 embryos, but embryo location remained similar $(P>0.05)$ to that of the expected distribution.

The percentage of living embryos was similar $(P>0.05)$ in the right and left uterine horns (Table 2 ). When the total amount of nitrogen in the conceptus was equivalent to $1 \cdot 0$, that proportion for embryonic development increased $(P<0.01)$ between Days 14 and 34. The ratio of nitrogen in the embryo and placenta increased linearly by 0.0082 /day.

The nitrogen content of the embryo in relation to its position within the uterine horn indicated that development was similar $(P>0.05)$ for embryos located at either end of the horn and comparable $(P>0.05)$ to those located in the middle segment of the horn at each stage between Days 14 and 34 after mating (Table 3$)$. The placental nitrogen contents were similar $(P>0.05)$ regardless of their location within the horn at each stage between Days 14 and 34.

The proportion of nitrogen in the embryo as related to the number of embryos within the uterine horn is shown in Table 4. As the number of embryos in a horn increased from 1 to 11, the proportion of nitrogen in each embryo remained similar $(P>0.05)$ to the expected theoretical values for that size of group. The embryo nearest the utero-tubal junction (Embryo 1) contained an amount of nitrogen similar $(P>0.05)$ to that found in Embryo $n$. The proportion of nitrogen in each placenta remained similar $(P>0.05)$ to expected theoretical values for each group size. The proportional amount of nitrogen in Placenta 1 was similar $(P>0.05)$ to that found in Placentae 2 to $n$, and this relationship was consistent for uterine horns containing 1-11 placentae.

\section{Discussion}

In the pig, eggs are fertilized in the ampullary portion of the oviduct, and the embryos then enter the uterus in the 4- to 8-celled stage of development about $48 \mathrm{hr}$ after ovulation (Perry \& Rowlands, 1962). Intrauterine migration and spacing of the embryos occur between Days 4 and 12, whereas embryo-endometrial attachment proceeds at Days 11-13, and implantation progresses between Days 12 and 18 (Short, 1969; Anderson, 1974). Intrauterine spacing of the developing blastocysts therefore occurs during a period of about 6 days. 


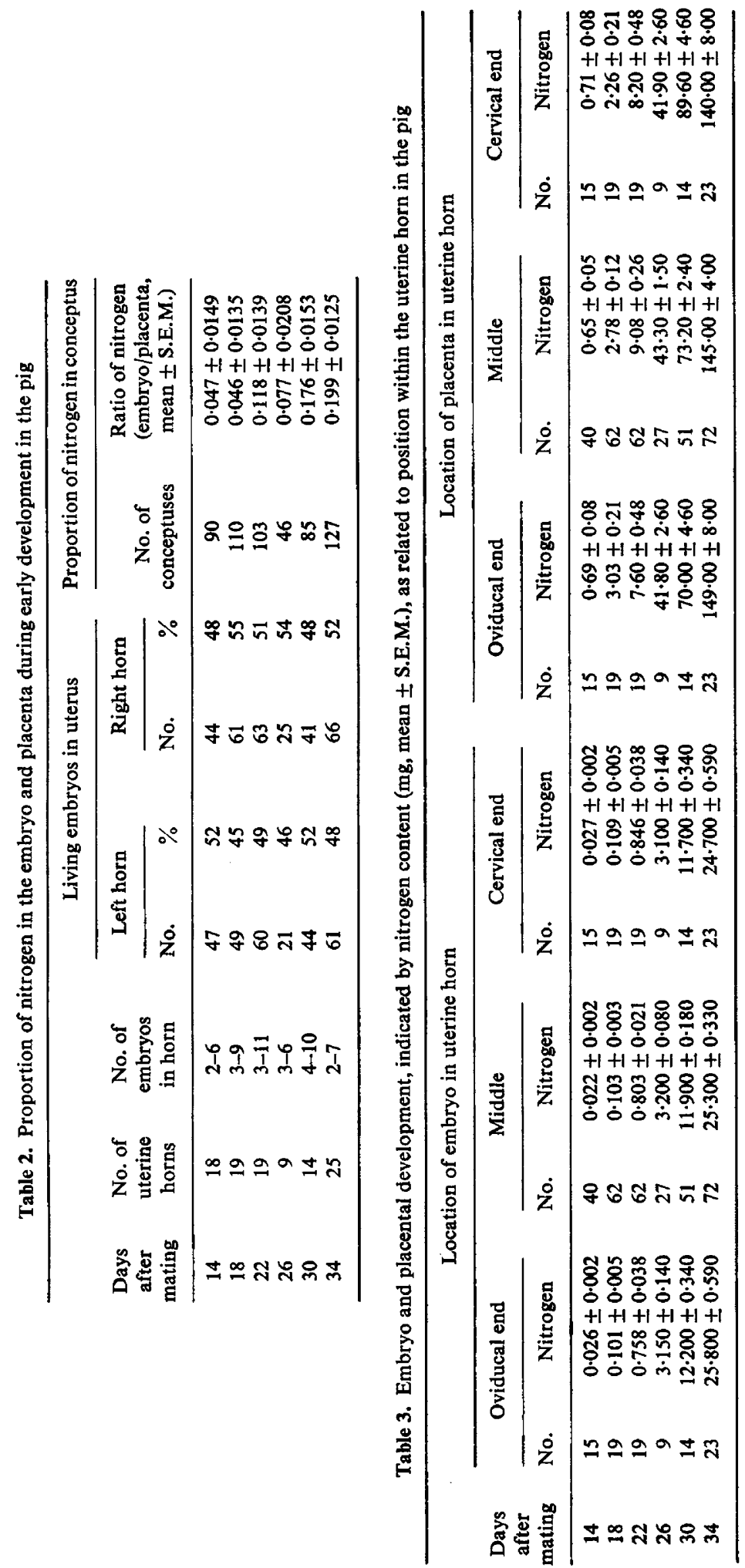




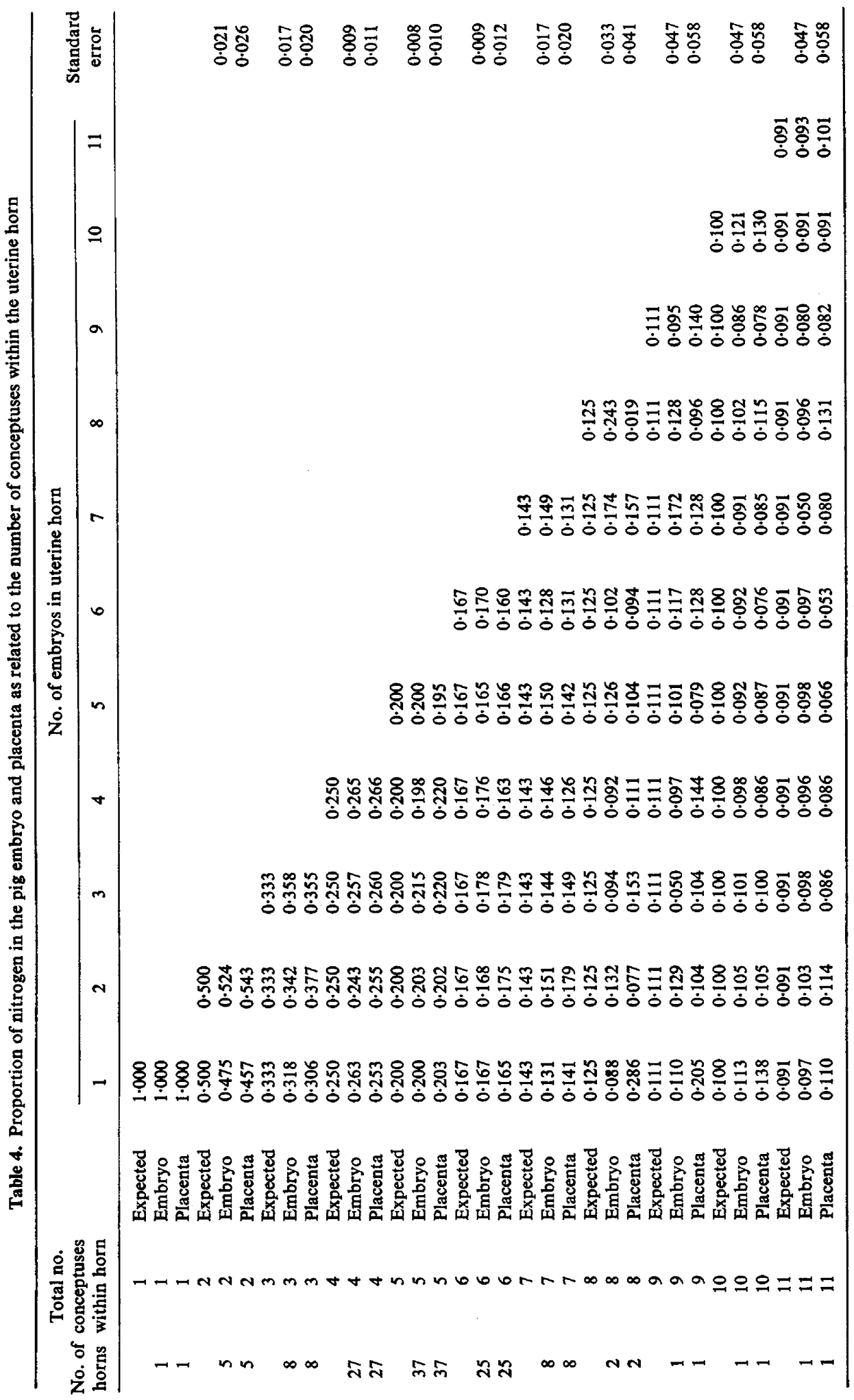


In the present study, the embryo nearest the utero-tubal junction (Embryo 1) or the one nearest the cervix (Embryo $n$ ) was closer to the extremities of the uterine horn than the expected theoretical distributions for horns containing up to 7 embryos, but for horns containing 2-11 embryos the embryos were evenly and consistently spaced within the uterine horn between Days 14 and 34 after mating. The distribution throughout the horn of embryos with similar amounts of nitrogen agrees with the findings of Legault \& Leuillet (1973) on the distribution of embryos of similar weight during early pregnancy in the pig. Reduced embryo and placental development during prolonged inanition in the pig (Anderson, 1975) was unrelated to location of embryo within the uterine horn.

Placental development, as indicated by proportional amounts of nitrogen in the placentae, remained similar in all locations within the uterine horn during early pregnancy. Legault \& Leuillet (1973) found, however, that wet weights of placentae were higher for those located at the utero-tubal and cervical ends of the uterine horn by Day 30 of pregnancy. During the period of 14-34 days after mating in the present investigation, the embryo was developing at a proportionally greater rate, as indicated by nitrogen content, than its placenta. Only the proportional amount of nitrogen was reduced in the embryo and its placenta when the number of them increased from 1 to 11 per horn. There did not seem to be any relationship between the vascular arrangement or blood supply to particular segments of the uterine horn and embryonic or placental development during the first 30 days of pregnancy. Although fetal weight was greater in those fetuses located near the utero-tubal and cervical ends of the uterine horn during late stages of pregnancy (Waldorf et al., 1957), Perry \& Rowell (1969) found no consistent relationship between uterine vasculature and fetal weight.

In this investigation, the mean ovulation rate was 10.6 , and embryo survival rate $88.9 \%$ in 64 pigs. Webel \& Dziuk (1974) indicated that embryonic mortality before Day 30 was not associated with limitations in intrauterine space, but after Day 30 it may be a factor in fetal death, particularly when large numbers of fetuses are present or when intrauterine space is restricted.

This is Journal Paper No. J-8236 of the Iowa Agriculture and Home Economics Experiment Station, Ames, Iowa; Projects No. 1325 and 1712.

We thank Dr W. P. Switzer and Dr D. O. Farrington of the Veterinary Medical Research Institute for monitoring the health of the experimental animals, Dr R. M. Melampy for advice, Dr D. F. Cox of the Department of Statistics for advice and assistance on statistical analyses, and Mr M. E. Shell, Mr D. L. Plath and Mr C. R. Bohnker for technical assistance.

\section{References}

ANDERSON, L.L. (1974) Early embryonic development in the pig. J. Anim. Sci. 39, 986, Abstr.

ANDERSON, L.L. (1975) Embryonic and placental development during prolonged inanition in the pig. Am. J. Physiol. (In press).

Legault, C. \& Leuillet, M. (1973) Étude de quelques facteurs de variation du poids de l'embryon et du placenta chez la truie primipare au trentième jour de la gestation. Annls Biol. anim. Biochim. Biophys. 13, 25-36.

Lowry, O.H., Rosebrough, N.J., FARR, A.L. \& RANDALL, R.J. (1951) Protein measurement with the Folin phenol reagent. J. biol. Chem. 193, 265-275.

PERry, J.S. \& Rowell, J.G. (1969) Variations in foetal weight and vascular supply along the uterine horn of the pig. J. Reprod. Fert. 19, 527-534.

PeRry, J.S. \& Rowlands, I.W. (1962) Early pregnancy in the pig. J. Reprod. Fert. 4, 175-188.

SHORT, R.V. (1969) Implantation and maternal recognition of pregnancy. In Foetal Autonomy, pp. 2-31. Eds G. E. W. Wolstenholme \& M. O'Connor. J. and A. Churchill, London. Waldorf, D.P., Foote, W.C., Self, H.L., Chapman, A.B. \& Casida, L.E. (1957) Factors affecting fetal pig weight late in gestation. J. Anim. Sci. 16, 976-985. WeBel, S.K. \& DzIUK, P.J. (1974) Effect of stage of gestation and uterine space on prenatal survival in the pig. J. Anim. Sci. 38, 960-963.

Received 14 July 1975 